\title{
Biventricular Pacing in the Early Postoperative Period After Cardiac Surgery
}

\author{
F. STRAKA ${ }^{1}$, J. PIRK ${ }^{1}$, M. PINĎÁK ${ }^{1}$, I. SKALSKÝ ${ }^{1}$, V. VANČURA ${ }^{1}$, R. ČIHÁK ${ }^{1}$, \\ T. MAREK ${ }^{1}$, P. LUPÍNEK ${ }^{1}$, D. SCHORNÍK ${ }^{1}$, J. MAŚÍN ${ }^{1}$, M. ZEMAN ${ }^{3}$, J. ŠKROBÁKOVÁ ${ }^{1}$, \\ Z. DORAZILOVÁ ${ }^{1}$, J. SKIBOVÁ ${ }^{2}$
}

${ }^{1}$ Heart Centre, Institute for Clinical and Experimental Medicine, Prague, Czech Republic, ${ }^{2}$ Medical Statistics Unit, Institute for Clinical and Experimental Medicine, Prague, Czech Republic, ${ }^{3}$ Medtronic Czechia, Prague, Czech Republic

Received July 29, 2010

Accepted August 4, 2011

On-line October 12, 2011

\section{Summary}

Cardiac resynchronization therapy is not commonly used in the early postoperative period in patients undergoing cardiac surgery who have left ventricular (LV) dysfunction and a history of heart failure. We performed a prospective randomized clinical trial to compare atrial synchronous right ventricular (DDD RV) and biventricular (DDD BIV) pacing within 72 hours after cardiac surgery in patients with an EF $\leq 35 \%$, a QRS interval longer than 120 msec and who had LV dyssynchrony detected by real-time three-dimensional echocardiography (RT3DE). Epicardial pacing was provided by a modified Medtronic INSYNC III pacemaker. An LV epicardial pacing lead was implanted on the latest activated segment of the LV based on RT3DE. The study included 18 patients with ischemic heart disease, with or without valvular heart disease (14 men, 4 women, average age 71 years). Patients undergoing DDD BIV pacing had a statistically significant greater $\mathrm{CO}$ and $\mathrm{CI}$ (CO $6.7 \pm 1.8 \mathrm{l} / \mathrm{min}, \mathrm{CI} 3.4 \pm 0.7 \mathrm{l} / \mathrm{min} / \mathrm{m}^{2}$ ) than patients undergoing DDD RV pacing (CO $5.5 \pm 1.4 \mathrm{l} / \mathrm{min}, \mathrm{CI} 2.8 \pm 0.7$ $\left.\mathrm{l} / \mathrm{min} / \mathrm{m}^{2}\right), \mathrm{p}<0.001$. DDD BIV pacing in the early postoperative period after cardiac surgery corrects LV dyssynchrony and has better hemodynamic results than DDD RV pacing.

\section{Key words}

Cardiac resynchronization therapy - Cardiac surgery - RT3DE echocardiography $\bullet$ Heart failure $\bullet$ Hemodynamics

\section{Corresponding author}

F. Straka, Department of Cardiac Surgery, Institute for Clinical and Experimental Medicine, Vídeňská 1958/9, 14021 Prague, Czech Republic. Fax: 420-26136 2799. E-mail: frst@ikem.cz

\section{Introduction}

The postoperative period in patients with left ventricular (LV) dysfunction having a LV ejection fraction $(E F) \leq 35 \%$ is prolonged, with a need for extended inotropic support therapy, prolonged mechanical ventilation or stay in the intensive care unit (Nalysnyk et al. 2003). Standard postoperative care at the present time involves atrial synchronous right ventricular (DDD RV) pacing in the case of bradycardia or conduction disturbances. Although it is well known that RV pacing may induce ECG signs of left bundle branch block (LBBB) and LV mechanical dyssynchrony, cardiac resynchronization therapy (CRT) is not routinely used in this high risk group of patients immediately after surgery. The objective of our study was to compare the hemodynamic effect of echocardiographically optimized DDD RV pacing to DDD biventricular (BIV) pacing in patients with LV dysfunction who had mechanical dyssynchrony in the early postoperative period after cardiac surgery. Real-time three-dimensional echocardiography (RT3DE) was used preoperatively as a new approach for detecting LV mechanical dysynchrony and the latest activated segment of the LV for targeted LV epicardial lead placement.

\section{Methods}

Our prospective randomized study included patients with sinus rhythm preoperatively a New York 
Heart Association (NYHA) functional class II-IV despite optimal pharmacologic therapy, a history of heart failure due to ischemic cardiomyopathy with severe LV dysfunction, an $\mathrm{EF} \leq 35 \%$, a QRS longer than $120 \mathrm{msec}$ with preoperatively detected LV dyssynchrony by RT3DE. The patients were then scheduled for myocardial revascularization without LV myocardial resection (aneurysmectomy) and randomized to undergo DDD RV or DDD BIV pacing in the first 72 hours after cardiac surgery. Randomization was carried out after an informed consent form had been signed.

\section{Echocardiography}

Two-dimensional (2D) echocardiography measurements were performed according to the guidelines of the American Society of Echocardiography (Lang et al. 2005). To measure the mitral inflow velocity, the sample volume of the pulsed Doppler was placed at the mitral valve tips in the apical four-chamber view. The LV outflow velocity was measured from the apical long axis view with the sample volume of the pulsed Doppler just below the aortic annulus.

We used RT3DE to detect LV dyssynchrony before surgery. Acquisitions were made on the Philips iE33 echocardiography machine (iE33 Philips, Andover, MA) using an X3-1 matrix-array transducer. Seven consecutive heart cycles and a constant RR interval were used to create a full-volume acquisition of the LV from the apical window. We used Philips 3DQADV, QLAB, Version 4.2 software that enables semi-automatic endocardial border detection and shows global time to minimum systolic LV volume curves during the cardiac cycle. In this manner we calculated LV volumes (endsystolic volume - LVESV, end-diastolic volume LVEDV) and LVEF. For evaluating mechanical dyssynchrony we used the 16 segment LV model described by the American Society of Echocardiography (Lang et al. 2005). The LV systolic dyssynchrony index (SDI) was calculated as the standard deviation of the time to minimal systolic volume for all 16 segments (Tmsv 16-SD), expressed as a percentage of the RR interval, thus eliminating the effects of heart rate variability (Park et al. 2007, Marsan et al. 2008). We used a cut-off value of SDI $\geq 6 \%$ to define LV mechanical dyssynchrony. The latest activated segment of the LV was established with "timing bull's eye parametric imaging" using 3DQ-Advanced QLAB software, Version 4.2, Philips, the Netherlands. The global Tmsv 16-SD as a timing reference was coded in green, early contracting segments were coded in blue, and the latest contracting segments were coded in red/yellow, as described by Soliman et al. (2009).

\section{Surgical management}

The cardiopulmonary bypass (CPB) circuit was primed with $1000 \mathrm{ml}$ of Ringer's solution and $250 \mathrm{ml}$ of $20 \%$ mannitol. A nonpulsatile flow of $2.41 / \mathrm{min} / \mathrm{m}^{2}$ was established using a membrane oxygenator D703 (Dideco, Italy). Myocardial protection was obtained using cold blood cardioplegic solution. The patients were cooled to $33{ }^{\circ} \mathrm{C}$ and perfusion pressure was maintained in the range of $40 \mathrm{~mm} \mathrm{Hg}$ to $70 \mathrm{~mm} \mathrm{Hg}$. The postoperative intensive care was standardized and extubation was performed in hemodynamically stable patients after a period of gradual weaning from mechanical ventilatory support.

\section{Cardiac pacing therapy}

Pacing epicardial leads were placed at the end of the operation before sternal closure. Targeted DDD BIV pacing using the Medtronic bipolar lead system (bipolar coaxial 6495, Medtronic Inc, Minneapolis, MN, USA) was performed by placing an epicardial LV electrode on the latest activated segment of the LV based on RT3DE. Other leads were placed on the RV approximately $1-2 \mathrm{~cm}$ paraseptally in the lower third of the exposed anterior wall (not on the apex) and on the exposed wall of the right atrium (RA) below the confluence of the superior vena cava (the location of the SA node). The electrode impedance, sensing and pacing thresholds were measured during surgery - a satisfactory threshold was $\leq 3 \mathrm{~V} / 0.5 \mathrm{~ms}$. Correct lead placement was documented during surgery by transesophageal echocardiography and after surgery by chest X-ray. In the early postoperative period, the patients underwent optimization of pacing under echocardiography control (Vivid i GE echocardiography). The atrioventricular delay (AVD) was optimized by measuring the velocity time integral (VTI) of the transmitral flow. Optimum AVD was defined as the AVD resulting in the highest VTI when the A wave of transmitral flow is not truncated. When optimizing the interventricular delay (VVD) we measured the maximal VTI in the LV outflow tract. The pacing rate was $90 \mathrm{bpm}$. Pacing was provided by a modified Medtronic INSYNC III pacemaker and pacemaker programming was done by a Medtronic programmer.

\section{Hemodynamic measurements}

Invasive measurements at the individual pacing 
modes were performed using a Swan-Ganz 7.5 F/110 cm thermodilution catheter (Edwards Lifesciences LLC Irwine CA). These measurements included mean pulmonary artery pressure (MPAP), cardiac output (CO), cardiac index (CI), pulmonary vascular resistance index (PVRI), systemic vascular resistance index (SVRI), left ventricular stroke work index (LVSWI) and right ventricular stroke work index (RVSWI). The mean arterial pressure (MAP) was measured using a 20G/80 mm radial artery catheter (Arteriofix art.-Kath.Set- B. Braun Melsugen AG). Measurements were performed immediately after surgery upon arrival in the ICU at the initial pacing mode that was assigned to each patient preoperatively (DDD RV or DDD BIV). Then after a 20 minute washout period the pacing mode was changed (DDD RV to DDD BIV or DDD BIV to DDD $\mathrm{RV}$ ) and the measurements were repeated. The patients were then returned to the original pacing mode to which they were randomized. A similar series of measurements were performed at 24,48 and 72 hours after surgery. A comparison between the hemodynamic effect of RV and BIV pacing could therefore be made for each patient. Intravenous drug infusions and inotrope doses were not changed during the measurements. Other patient postoperative therapy was carried out in a standard way, as established for cardiac surgery patients. The inotropic therapy used postoperatively in our study included milrinone (Corotrop; Sanofi-Synthelabo, France) and dobutamine (Dobutamin Lachema; Pliva-Lachema, Czech Republic). Noradrenaline (Noradrenalin; Zentiva, Czech Republic) was administered only when necessary to maintain a target MAP of $70 \mathrm{~mm} \mathrm{Hg}$ or higher. In the case of atrial fibrillation, the measurements were carried out after conversion to a sinus rhythm using amiodarone or electric cardioversion.

\section{Statistical analysis}

The parameters were expressed as mean values \pm standard deviation or frequencies. A paired t-test was used for comparison of the two pacing modes (DDD RV and DDD BIV). All tests were two sided with $\mathrm{p}<0.05$ considered statistically significant. The statistical analyses were performed using Microsoft Excel and BMDP Statistical Software.

\section{Results}

The clinical and echocardiographic characteristics of the study group are described in
Table 1. Clinical characteristics and preoperative echocardiographic parameters of the study population $(n=18)$.

\begin{tabular}{lc}
\hline Age (years) & $71 \pm 9$ \\
Gender & 14 men, 4 women \\
BMI $\left(\mathrm{kg} / \mathrm{m}^{2}\right)$ & $27.8 \pm 5$ \\
Ischemic heart disease (pts) & 18 \\
PFO (pts) & 1 \\
Past medical history of hypertension & 16 \\
(pts) & \\
Hyperlipoproteinemia (pts) & 12 \\
Diabetes mellitus (pts) & 6 \\
LVEDD (mm) & $65 \pm 5$ \\
LVESD (mm) & $50 \pm 9$ \\
LVEDV (ml) & $180 \pm 50$ \\
LVESV (ml) & $134 \pm 42$ \\
LVEF (\%) & $25 \pm 4$ \\
LA PLAX (mm) & $47 \pm 5$ \\
LA A4C (mm) & $62 \pm 8$ \\
Severe mitral valve insufficiency & 8 \\
(pts) & \\
Severe aortic valve insufficiency & 3 \\
(pts) & \\
Severe tricuspid valve insufficiency & \\
(pts) & \\
SDI (\%) & \\
\hline & \\
\hline &
\end{tabular}

Data is presented as mean \pm S.D. or number $(n)$. Pts = patients. LVEDD = left ventricular end-diastolic diameter, LVESD = left ventricular end-systolic diameter, LVEDV = left ventricular enddistolic volume, LVESV = left ventricular end-systolic volume, LVEF = left ventricular ejection fraction, LS PLAX= left atrium parasternal long axis diameter, LS A4C = left atrium apical four chamber diameter, SDI = systolic dyssynchrony index measured by RT3DE.

Table 1 . The average age of our patients was $71 \pm 9$ years, and the majority were men (77.8 \% patients). All patients had echocardiographically proven LV enlargement and an average LVEF $26 \pm 4 \%$. Almost one half had severe mitral valve insufficiency ( $44.4 \%$ patients). All patients in our study had preoperative LV dyssynchrony (SDI $\geq 6 \%$ ) as measured by RT3DE (Fig. 1).

The surgery that was performed (Table 2), included coronary artery bypass grafting with or without a valve procedure. An aortoplasty was also performed in two patients to dilate the aortic root. Epicardial electrodes were placed on the latest activated segment of the LV at the end of surgery based on preoperative RT3DE (Fig. 2). The implantation of epicardial pacing leads did not significantly extend the duration of the surgery. 
Table 2. Performed cardiothoracic surgery $(n=18)$.

\begin{tabular}{lc} 
CABG - number of & $18 / 3.5$ \\
patients/average number of grafts & \\
in patients & \\
MVP (pts) & 4 \\
MVR (pts) & 4 \\
AVR (pts) & 3 \\
TVP (pts & 2 \\
Aortoplasty (pts) & 2 \\
Aortic cross-clamp time (min, mean & $62 \pm 32$ \\
\pm S.D.) & \\
Cardiopulmonary bypass time (min, & $112 \pm 34$ \\
mean \pm S.D.) & \\
\hline
\end{tabular}

Data is presented as mean \pm S.D. or number $(n)$. Pts = patients. $\mathrm{CABG}=$ coronary artery bypass grafting, $\mathrm{MVP}=$ mitral valve valvuloplasty, $M V R=$ mitral valve replacement, $A V R=$ aortic valve replacement, TVP = tricuspid valve valvuloplasty.

The most frequent LV epicardial electrode position was on the mid anterolateral segment in 7 patients. Other LV pacing lead postions were basal anterolateral in 4 patients, basal inferolateral in 4 patients and mid inferolateral in 3 patients.

The optimal pacing AVD and VVD were established for each patient before recording hemodynamic measurements, as described in methods. The mean optimal paced AVD was 150-170 ms, the mean optimal VVD was 15-20 ms for LV pre-activation (61\% of patients) and 12-15 ms for RV pre-activation (39\% of patients).

The inotropic support therapy was not changed during the hemodynamic measurements. 13 out of 18 patients received dobutamine (up to $5.0 \mu \mathrm{g} / \mathrm{kg} / \mathrm{min}$ ) and 6 out of 18 patients received milrinone (0.2-0.3 $\mu \mathrm{g} / \mathrm{kg} / \mathrm{min})$. Noradrenaline was administered to 3 out of 18 patients at a mean dose of $0.06 \mu \mathrm{g} / \mathrm{kg} / \mathrm{min}$.

The postoperative hemodynamic parameters during DDD RV and DDD BIV pacing are shown in Table 3. Since hemodynamic parameters did not change significantly during the postoperative period, all calculated hemodynamic values are average values of all measurements performed immediately after surgery, and at 24, 48 and 72 hours postoperatively. During DDD BIV pacing patients had a statistically significant greater $\mathrm{CO}$ and $\mathrm{CI}$ (CO $\left.6.7 \pm 1.8 \mathrm{l} / \mathrm{min}, \mathrm{CI} 3.4 \pm 0.7 \mathrm{1} / \mathrm{min} / \mathrm{m}^{2}\right)$ than during DDD RV pacing (CO 5.5 $\pm 1.4 \mathrm{l} / \mathrm{min}$, CI $2.8 \pm 0.7$ $1 / \mathrm{min} / \mathrm{m}^{2}$ ), DDD BIV vs. DDD RV $\mathrm{p} \leq 0.001$. Patients undergoing DDD BIV pacing also had a statistically
Table 3. Hemodynamic parameters during RV and BIV pacing $(n=18)$.

\begin{tabular}{lccc}
\hline & $\begin{array}{c}\text { RV } \\
\text { pacing }\end{array}$ & $\begin{array}{c}\text { BIV } \\
\text { pacing }\end{array}$ & $\begin{array}{c}\text { p } \\
\text { value }\end{array}$ \\
\hline MAP $(\mathrm{mm} \mathrm{Hg})$ & $74 \pm 9.4$ & $77.3 \pm 10.2$ & $\mathrm{p}=0.068$ \\
MPAP $(\mathrm{mm} \mathrm{Hg})$ & $24.4 \pm 5.2$ & $22.6 \pm 4.7$ & $\mathrm{p}<0.05$ \\
CO $(\mathrm{l} / \mathrm{min})$ & $5.5 \pm 1.4$ & $6.7 \pm 1.8$ & $\mathrm{p}<0.001$ \\
CI $\left(\mathrm{l} / \mathrm{min} / \mathrm{m}^{2}\right)$ & $2.8 \pm 0.7$ & $3.4 \pm 0.7$ & $\mathrm{p}<0.001$ \\
SVRI & $1830 \pm 356$ & $1620 \pm 443$ & $\mathrm{p}=0.019$ \\
$\left(\right.$ dyne $\left.\cdot \mathrm{sec} \cdot \mathrm{cm}^{-5} / \mathrm{m}^{2}\right)$ & & & \\
PVRI & $331 \pm 124$ & $303 \pm 151$ & $\mathrm{NS}$ \\
$\left(\right.$ dyne $\left.\cdot \mathrm{sec} \cdot \mathrm{cm}^{-5} / \mathrm{m}^{2}\right)$ & & & \\
LVSWI $\left(\mathrm{g} \cdot \mathrm{m}^{2} \mathrm{~m}^{2}\right)$ & $29.3 \pm 10.3$ & $34.4 \pm 10.1$ & $\mathrm{p}<0.001$ \\
RVSWI $\left(\mathrm{g} \cdot \mathrm{m} / \mathrm{m}^{2}\right)$ & $6.9 \pm 2.5$ & $8.4 \pm 2.8$ & $\mathrm{p}<0.001$ \\
\hline
\end{tabular}

The data is presented as mean \pm S.D. of 4 measurements performed immediately after surgery and 24,48 and $72 \mathrm{~h}$ after surgery. $\mathrm{MAP}=$ mean arterial pressure, $\mathrm{MPAP}=$ mean pulmonary artery pressure, $\mathrm{CO}=$ cardiac output, $\mathrm{CI}=$ cardiac index, $\mathrm{PVRI}=$ pulmonary vascular resistance index, SVRI $=$ systemic vascular resistance index, LVSWI = left ventricular stroke work index, RVSWI = right ventricular stroke work index. NS = nonsignificant.

significant lower MPAP, higher LVSWI and RVSWI which reflect better LV and RV function, respectively, as well as a statististically significant lower SVRI in comparison to patients undergoing DDD RV pacing. A lower PVRI and a higher MAP were also observed during DDD BIV pacing, although the difference was not statistically significant.

The early postoperative course during the first 72 hours after cardiac surgery was uncomplicated in our group of patients. There were no serious complications related to resynchronization therapy.

The average length of ICU stay was longer for patients randomized to DDD RV pacing (4.0 \pm 2.4 days) than for patients randomized to DDD BIV pacing $(3.0 \pm 1.8$ days). In eleven $(61 \%)$ of our patients a permanent BIV/ICD pacemaker was implanted for longterm cardiac resynchronization therapy and treatment of ventricular arrythmias. Seven (39\%) of our patients are being followed-up for the potential need of device implantation in the future.

\section{Discussion}

The prevalence of chronic heart failure in the general population ranges from 1 to $5 \%$, and hence there is 


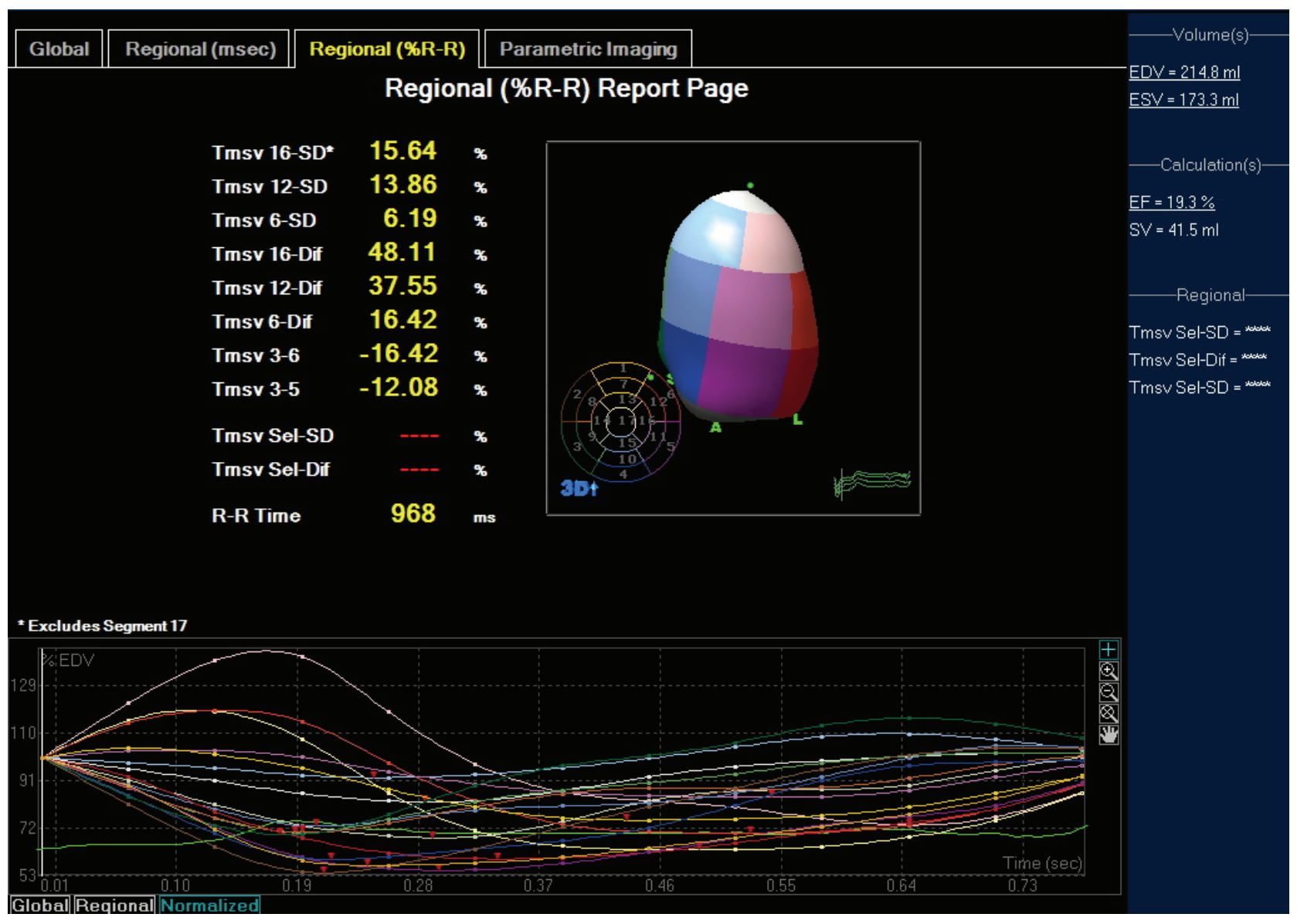

Fig. 1. Example of left ventricular (LV) dyssynchrony analysis (volumetric regional curves of 16 LV segments using RT3DE) before biventricular pacing in a patient with severe mechanical dyssynchrony, systolic dyssynchrony index (SDI) $\geq 15 \%$.

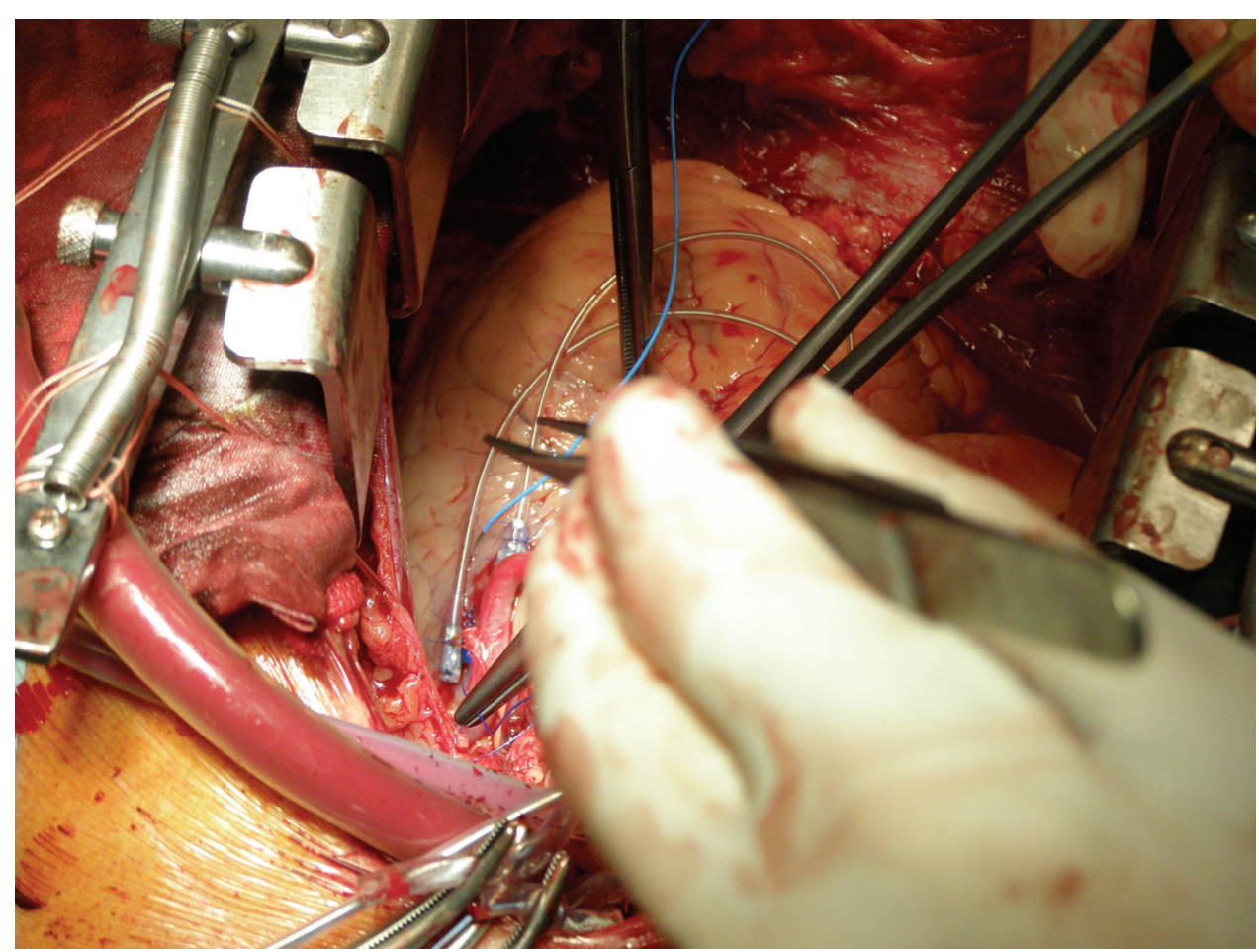

Fig. 2. Peroperative LV epicardial pacing lead placement on the latest activated segment of the LV based on RT3DE. 
an increasing proportion of patients presenting for cardiac surgery who have a dilated and dysfunctional LV with an $\mathrm{EF} \leq 35 \%$, or reduced functional capacity with a history of repeated hospital stay due to heart failure. Several clinical studies have demonstrated the favorable effect of CRT in improving functional classification and stress tolerance in patients with LV dysfunction, chronic heart failure and a New York Heart Association (NYHA) III/IV. As supported by completed trials, CRT also positively influences overall patient morbidity and mortality (The CARE-HF study - Cleland et al. 2001, COMPANION trial - Saxon et al. 2006). The recently performed MADITCRT trial (Moss et al. 2009) has shown that CRT combined with an implantable cardioverter defibrillator (ICD) decreased the risk of heart failure events in less symptomatic patients (NYHA class I or II) with ischemic and nonischemic cardiomyopathy, a low EF and wide QRS complex. A $41 \%$ reduction in the risk of heart failure events was observed, primarily in a subgroup of patients with a QRS duration $>150$ msec. This confirms the importance of CRT even in mildly symptomatic patients who display evidence of mechanical LV dyssynchrony. In this trial CRT was also associated with a significant reduction in LV volumes and improvement in the LVEF. CRT is also associated with LV reverse remodeling and a reduction of mitral regurgitation grade (Senechal et al. 2010).

The objective of our study was to evaluate the feasibility and effectiveness of targeted CRT therapy in the early postoperative period after cardiac surgery, to see whether a similar improvement in hemodynamic status would be observed in this high risk group of patients. It is known that the prognosis of cardiac surgery patients deteriorates proportionately with the degree of LV dysfunction and a history of clinically overt heart failure (Nalysnyk et al. 2003). The most critical period for these patients is the early postoperative period, which in some cases requires the institution of an intraaortic balloon pump (IABP) or some other mode of mechanical circulatory support, the need for extended administration of catecholamines, prolonged mechanical ventilation, or stay in the postoperative ward (Nalysnyk et al. 2003). It is known that obout $9 \%$ of patients after $\mathrm{CABG}$ require pacing for atrioventricular block or sinus bradydardia (Bethea et al. 2005). In addition to LV dysfunction, the main contributing factor resulting in poor outcome in patients after cardiac surgery may include dyssynchrony of myocardial contraction which reduces the pumping efficacy of the heart. In many cases this is compounded by progressive mitral regurgitation leading to a reduced $\mathrm{CO}$ and CI. This negative pathophysiological cycle is often difficult to counter by catecholamine administration or mechanical circulatory support such as IABP. Dyssynchrony may be negatively influenced in the immediate postoperative period by standardly used DDD RV pacing. Liu et al. (2008) found that in patients with sick sinus syndrome, acute right ventricular apical pacing (RVA) worsened the myocardial performance index (with RVA pacing $0.42 \pm 0.18$ vs. without RVA pacing $0.31 \pm 14$ ) and lowered the LV ejection fraction as determined by RT3DE (with RVA 54.4 $\pm 7.7 \%$ vs. without RVA $56.7 \pm 7.9 \%, \mathrm{p}=0.013)$. In this study, RVA pacing also worsened the parameters of LV dyssynchrony evaluated by RT3DE SDI (with RVA 7.0 $\pm 2.54 \%$ vs. without RVA $5.36 \pm 2.17 \%$; $=0.003)$. The standard procedure of implanting only right-sided ventricular epicardial pacing leads results in slow spreading of depolarization through the working myocardium instead of a fast instantaneous spread by the specialized conduction system of the heart. Isolated RV pacing requires myocardial conduction of depolarization through the right ventricle to the left ventricle, which is slower than through the His-Purkinje system. This results in dyssynchrony between the two ventricles (Healy et al. 2008).

CRT has not been commonly used in patients after cardiac surgery, and thus there is an ongoing discussion concerning its benefits and its optimal clinical application (Dzemali et al. 2006, Muehlschlegel et al. 2008, Hanke et al. 2009). The proper selection of patients for CRT remains a challenge. It is known that the diagnostic criterion of LV dyssynchrony is not only a wide QRS, but that even patients with a normal QRS interval may have signs of LV dyssynchrony (Achilli et al. 2003). Currently, there is an attempt to find the optimal echocardiographic or other method for diagnosing LV dyssynchrony that is reliable and predictive of the response to resynchronization therapy. The multicenter PROSPECT trial (Chung et al. 2008) showed great variability in the measurement of a wide range of echocardiographic parameters that were used to diagnose LV dyssynchrony. A very promising method in detecting LV dyssynchrony is RT3DE, which was used in our study. It is possible to establish LV dyssynchrony based on the systolic dyssynchrony index value (SDI). Kleijn et al. (2009) reported the optimal cutoff value for SDI by RT3DE to be $6.7 \%$, which yielded sensitivity of $90 \%$ and specificity of $87 \%$ in predicting the clinical response to CRT, and sensitivity of $88 \%$ and specificity of $70 \%$ in predicting 
reverse remodeling. Marshan et al. (2008) found a cutoff value for SDI $\geq 5.6 \%$, which has sensitivity of $88 \%$ and specificity of $86 \%$ in predicting an acute response to CRT. In our group of patients, the cutoff value of SDI of $\geq 6.0 \%$ by RT3DE was connected with improved hemodynamic results during DDD BIV pacing in comparison to DDD $\mathrm{RV}$ pacing. In our opinion, this cutoff value of SDI by RT3DE can be used for selecting patients who will benefit from DDD BIV pacing in the early postoperative period after cardiac surgery. However, our results need to be confirmed by larger studies.

There is much controversy regarding the optimal site for pacing lead placement and the best pacing mode in heart failure patients (Butter et al. 2001, Dzemali et al. 2006, Hanke et al. 2009). There is also great individual variability in the optimal site for LV pacing during CRT (Dekker et al. 2004). Murphy et al. (2006) found that placing the LV electrode at the site of maximal delay is in concordance with LV reverse remodeling and improvement in NYHA class. Merchant et al. (2010) in their study compared apical LV lead placement with basal/midventricle lead placement. The event free survival (primary outcome was heart failure hospitalization, cardiac transplantation, or all-cause mortality) was better in the basal/midventricle lead placement group (79\%) than in the apical lead placement group (52\%), hazard ratio [HR] 2.7 (95\% CI: 1.5-5.5, $\mathrm{p}=0.006$ ). The apical lead placement group also had less improvement in NYHA functional class and less LV reverse remodeling. The explanation for this finding is that pacing in the region of less delayed electrical and mechanical activation cannot adequately correct LV electrical and mechanical dyssynchrony. Ansalone et al. (2002) published that in $43 \%$ of patients indicated for CRT the latest activated segment was not in the free lateral or posterolateral wall, which is the common position used during transvenous LV lead placement. In our study we used a new approach where the LV lead was surgically affixed to the site of latest LV activation as determined by RT3DE. This was most frequently in the mid anterolateral segment. A surgical approach for lead placement, in comparison to the transvenous approach, allows accurate placement of the LV pacing lead without the anatomical limitations imposed by cardiac veins. It also allows the surgeon to avoid areas of scarred myocardium and therefore areas of slow conduction (Eberhardt et al. 2007).

To optimize AVD and VVD we used conventional Doppler echocardiography, as described by Jansen et al. (2006). An optimal AVD and VVD combination is very important in patients with heart failure because it correlates with an improvement in clinical performance status and LV reverse remodeling (Sutton et al. 2006). AVD optimization during CRT achieves optimimal LV filling and atrial emptying, and reduces diastolic mitral regurgitation. VVD optimization improves ventricular dyssynchrony leading to a more effective ventricular output.

Hemodynamic monitoring in our study enabled a comparison of two pacing modes in patients after cardiac surgery, DDD BIV pacing and standard DDD RV pacing. Our current results show that targeted DDD BIV pacing in patients with LV dysfunction and heart failure in the early period after cardiac surgery improved hemodynamic parameters $(\mathrm{CO}, \mathrm{CI})$ and was significantly better than DDD RV pacing. The feasibility and safety of temporary DDD BIV pacing were demonstrated previously in the study by Eberhard et al. (2007), and similar positive results have been reported by Dzemali et al. (2008) and Hanke et al. (2009). In a recent study by Wang et al. (2011), temporary biventricular pacing increased intraoperative $\mathrm{CO}$ in patients with LV dysfunction undergoing cardiac surgery. As in our study, the authors reported that AVD and VVD optimization improves this benefit. In our study we used a modified Medtronic INSYNC III pacemaker, but it is possible to use any external pacemaker that permits a DDD BIV pacing mode. Optimized DDD BIV pacing may shorten ICU stay in a high risk group of patients with ischemic heart disease, with or without concomitant valvular heart disease, in the early postoperative period after cardiac surgery in comparison to standardly used DDD RV pacing. Based on accepted guidelines (Dickstein et al. 2010), patients who are indicated for cardiothoracic surgery and who fulfill the criteria for CRT (LV dysfunction, EF $\leq 35 \%$, QRS $\geq 120$ ms, with signs of LV dyssynchrony) should undergo LV epicardial electrode implantation at the time of surgery with the possibility of long-term DDD BIV or DDD BIV/ICD therapy. Another application of CRT using a surgically implanted epicardial LV lead is in patients where optimal LV lead positioning cannot be achieved via the coronary sinus.

\section{Conflict of Interest}

There is no conflict of interest.

\section{Acknowledgements}

This study was supported by grant IGA $\mathrm{MH}$ CR NR/9384-3/2007 and by grant 1M0510 from the Ministry of Education of the Czech Republic. 


\section{References}

ACHILli A, SASSARA M, FICILI S, PONTILlO D, ACHILli P, ALESI C, De SPIRITO S, GUERRA R, PATRUNO N, SERRA F: Long-term effectiveness of cardiac resynchronization therapy in patients with refractory heart failure and „narrow" QRS. J Am Coll Cardiol 42: 2117-2124, 2003.

ANSALONE G, GIANNANTONI P, RICCI R, TRAMBAIOLO P, FEDELE F, SANTINI M: Doppler myocardial imaging to evaluate the effectiveness of pacing sites in patients receiving biventricular pacing. $J \mathrm{Am} \mathrm{Coll}$ Cardiol 39: 489-499, 2002.

BETHEA BT, SALAZAR JD, GREDA MA, DOTY JR, FITTON TP, ALEJO DE, BOROWITZ LM JR, GOTT VL, SUSSMAN MS, BAUMGARTNER WA: Determining the utility of temporary pacing wires after coronary artery bypass surgery. Ann Thorac Surg 79: 104-107, 2005.

BUTTER C, AURICCHIO A, STELLBRINK C, FLECK E, DING J, YU Y, HUVELLE E, SPINELI J: Effect of resynchronization therapy stimulation site on the systolic function of heart failure patients. Circulation 104: 3026-3029, 2001.

CHUNG ES, LEON AR, TAVAZZI L, SUN JP, NIHOYANNOPOULOS P, MERLINO J, ABRAHAM WT, GHIO S, LECLERCQ C, BAX JJ, YU CM, GORCSAN J 3RD, ST JOHN SUTTON M, DE SUTTER J, MURILLO J: Results of the Predictors of Response to CRT (PROSPECT) trial. Circulation 117: 2608-2616, 2008.

CLELAND J, FREEMANTLE N, GHIO S, FRUHWALD F, SHANKAR A, MARIJANOVSKI M, VERBOVEN Y, TAVAZZI L: Predicting the long-term effects of cardiac resynchronization therapy on mortality from baseline variables and the early response a report from the CARE-HF (Cardiac Resynchronization in Heart Failure) Trial. J Am Coll Cardiol 52: 438-445, 2008.

DEKKER A, PHELPS B, DIJKMAN B, VAN DER NAGEL T, VAN DER VEEN F, GESKES G, MAESSEN J: Epicardial left ventricular lead placement for cardiac resynchronization therapy: optimal pace site selection with pressurevolume loops. J Thorac Cardiovasc Surg 127: 1641-1647, 2004.

DICKSTEIN K, VARGAS PE, AURICCHIO A, DAUBERT JC, LINDE C, MCMURRAY J, PONIKOWSKI P, GIULIANA S, SUTTON R, VAN VELDHUISEN DJ: 2010 focused update of ESC guidelines on device therapy in heart failure. An update of the 2008 ESC guidelines for the diagnosis and treatment of acute and chronic heart failure and the 2007 ESC guidelines for cardiac resynchronization therapy. EHJ 31: 2677-2687, 2010.

DZEMALI O, BAKHTIARY F, DOGAN S, WITTLINGER T, MORITZ A, KLEINE P: Perioperative biventricular pacing leads to improvement of hemodynamics in patients with reduced left-ventricular function-interim results. Pacing Clin Electrophysiol 29: 1341-1345, 2006.

EBERHART F, HANKE T, HERINGLAKE M, MASSALME MS, BECHTEL M, MISFELD M, WIEGAND UK: Feasibility of temporary biventricular pacing in patients with reduced left ventricular function after coronary artery bypass grafting. Pacing Clin Electrophysiol 30 (Suppl 1): S50-S53, 2007.

HANKE T, MISFELD M, HERINGLAKE M, SCHREUDER JJ, WIEGAND UK, EBERHARDT F: The effect of biventricular pacing on cardiac function after weaning from cardiopulmonary bypass in patients with reduced left ventricular function: a pressure-volume loop analysis. J Thorac Cardiovasc Surg 138: 148-156, 2009.

HEALY DG, HARGROVE M, DODDAKULLA K, HINCHION J, O'DONNEL A, AHERNE T: Impact of pacing modality and biventricular pacing on cardiac output and coronary conduit flow in the post-cardiotomy patients. Interact Cardiovasc Thorac Surg 7: 805-808, 2008.

JANSEN AH, BRACKE FA, VAN DANTZIG JM, MEIER A, VAN DER VOORT PH, AARNOUDSE W, VAN GELDER BM, PEELS KH: Correlation of echo-doppler optimization of atrioventricular delay in cardiac resynchronization therapy with invasive hemodynamics in patients with heart failure secondary to ischemic or idiopathic dilated cardiomyopathy. Am J Cardiol 97: 552-557, 2006.

KLEIN SA, VAN DIJK J, DE COCK CC, ALAART CP, VAN ROSSUM AC, KAMP O: Assessment of intraventricular mechanical dyssynchrony and prediction of response to cardiac resynchronization therapy: comparison between tissue Doppler imaging and real-time three-dimensional echocardiography. $J$ Am Soc Echocardiogr 22: 1047-1054, 2009. 
LANG RM, BIERIG M, DEVEREUX RB, FLACHSKAMPF FA, FOSTER E, PELLIKKA PA, PICARD MH, ROMAN MJ, SEWARD J, SHANEWISE JS, SOLOMON SD, SPENCER KT, SUTTON MS, STEWARD WJ: Recommendations for chamber quantification: a report from the American Society of Echocardiography's Guidelines and Standards Committee and the Chamber Quantification Writing Group, developed in conjunction with the European Association of Echocardiography, a branch of the European Society of Cardiology. J Am Soc Echocardiogr 18: 1440-1463, 2005.

LIU WH, CHEN MC, CHEN YL, GUO BF, PAN KL, YANG CH, CHANG HW: Right ventricular apical pacing acutely impairs left ventricular function and induces mechanical dyssynchrony in patients with sick sinus syndrome: a real-time three-dimensional echocardiographic study. J Am Soc Echocardiogr 21: 224-229, 2008.

MARSAN NA, BLEEKER GB, YPENBURG C, GHIO S, VAN DE VEIRE NR, HOLMAN ER, VAN DER WALL EE, TAVAZZI L, SCHALIJ MJ, BAX JJ: Real-time threedimensional echocardiography permits quantification of left ventricular mechanical dyssynchrony and predicts acute response to cardiac resynchronization therapy. J Cardiovasc Electrophysiol 4: 392-399, 2008.

MERCHANT FM, HEIST EK, MCCARTY D, KUMAR P, DAS S, BLENDEA D, ELLINOR PT, MELA T, PICARD MH, RUSKIN JN, SINGH JP: Impact of segmental left ventricle lead position on cardiac resynchronization therapy outcomes. Heart Rhythm 7: 639-644, 2010.

MOSS AJ, HALL WJ, CANNOM DS, KLEIN H, BROWS W, DAUBERT JP, ESTES M, FOSTER E, GREENBERG H, HIGGINS SL, PFEFFER MA, SOLOMON SD, WILBER D, ZAREBA W, for the MADIT-CRT Trial Investigators: Cardiac-resynchronization therapy for the prevention of heart-failure events. $N$ Engl J Med 361: 1329-1338, 2009.

MUEHLSCHLEGEL JD, PENG YG, LOBATO EB, HESS PJ JR, MARTIN TD, KLODELL CT JR: Temporary biventricular pacing postcardiopulmonary bypass in patients with reduced ejection fraction. J Card Surg 23: 324-330, 2008.

MURPHY RT, SIGURDSSON G, MULAMALLA S, AGLER D, POPOVIC ZB, STARLING RC, WILKOFF BL, THOMAS JD, GRIMM RA: Tissu synchronization imaging and optimal left ventricular pacing site in cardiac resynchronization therapy. Am J Cardiol 97: 1615-1621, 2006.

NALYSNYK L, FAHRBACH K, REYNOLDS MW, ZHAO SZ, ROSS S: Adverse events in coronary artery bypass graft (CABG) trials: a systematic review and analysis. Heart 89: 767-772, 2003.

PARK SM, KIM KC, JEON MJ, LEE CK, KIM DH, PARK KS, LEE WH, KWAN J: Assessment of left ventricular asynchrony using volume-time curves of 16 segments by real-time 3 dimensional echocardiography: comparison with tissue Doppler imaging. Eur J Heart Fail 9: 62-67, 2007.

SAXON LA, BRISTOW MR, BOEHMER J, KRUEGER S, KASS DA, DE MARCO T, CARSON P, DICARLO L, FELDMAN AM, GALLE E, ECKLUND F: Predictors of sudden cardiac death and appropriate shock in the Comparison of Medical Therapy, Pacing, and Defibrillation in Heart Failure (COMPANION) Trial. Circulation 114: 2766-2772, 2006.

SENECHAL M, LANCELLOTTI P, MAGNE J, GARCEAU P, CHAMPAGNE J, PHILIPPON F, O'HARA G, MOONEN M, DUBOIS M: Impact of mitral regurgitation and myocardial viability on left ventricular reverse remodeling after cardiac resynchronization therapy in patients with ischemic cardiomyopathy. Am J Cardiol 106: 31-37, 2010.

SOLIMAN OII, VAN DALEN BM, NEMES A, VAN DER ZWAAN HB, VLETTER WB, TEN CATE FJ, THEUNS D, JORDAENS LJ, GELEIJNSE ML: Quantification of left ventricular systolic dyssynchrony by real-time threedimensional echocardiography. J Am Soc Echocardiogr 22: 232-239, 2009.

SUTTON MG, PLAPPERT T, HILPISCH KE, ABRAHAM WT, HAYES DL, CHINCHOY E: Sustained reverse left ventricular structural remodeling with cardiac resynchronization at one year is a function of etiology: quantitative Doppler echocardiographic evedence from the Multicenter InSync Randomized Clinical Evaluation (MIRACLE). Circulation 113: 266-272, 2006.

WANG DY, RICHMOND ME, QUINN A, MIRANI AJ, RUSANOV A, YALAMANCHI V, WEINBERG AD, CABRERIZA SE, SPONITZ HM: Optimized temporary biventricular pacing acutely improves intraoperative cardiac output after weaning from cardiopulmonary bypass: A substurdy of a randomized trial. $J$ Thorac Cardiovasc Surg 141: 1002-1008, 2011. 